\title{
Phosphate solubilizing rhizobacteria isolated from jujube ziziphus lotus plant stimulate wheat germination rate and seedlings growth
}

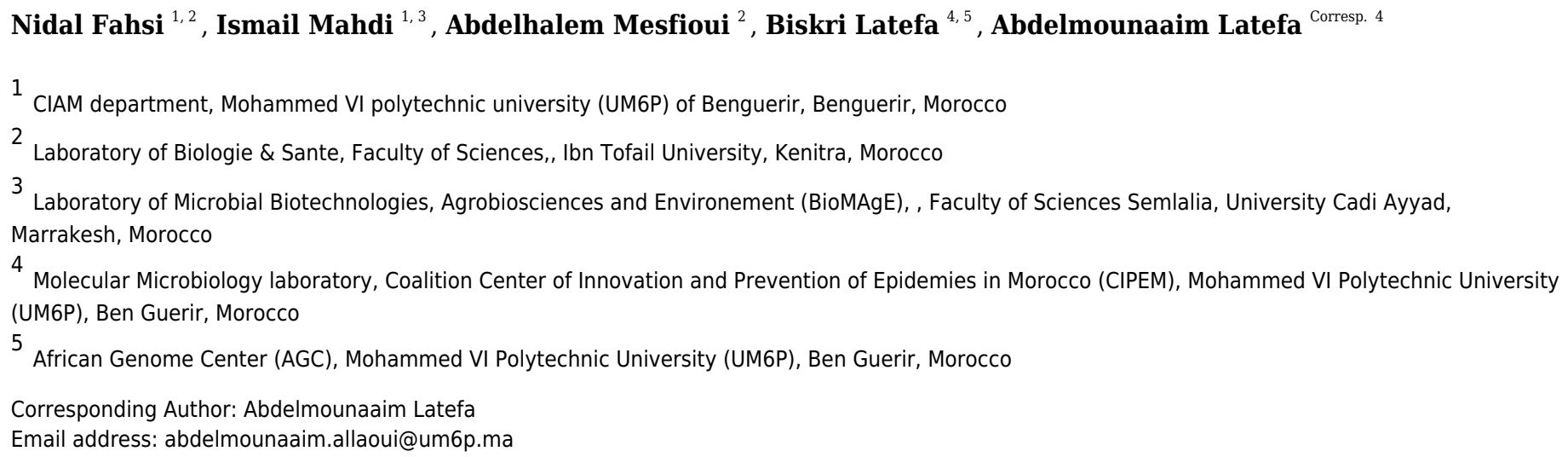

Jujube plant (Ziziphus lotus (L.) Desf.) can survive in arid climates and tolerates both biotic and abiotic stresses. Here, we isolated, for the first time in Morocco, nine phosphate solubilizing bacteria strains from jujube rhizosphere, designated $J 10$ to $J 13, J 15, \& J 153$ to J156. Genotypic identification based on 16S rDNA sequencing, revealed six strains that belong to Pseudomonas (J10, J12, J13, J15, J153 and J154), two to Bacillus (J11 and J156), and one to Paenibacillus J155. Siderophores were produced by all strains. Proteases activity was missing in Pseudomonas sp. J153 \& J154, whereas cellulase was restricted only to Pseudomonas sp. J10, Paenibacillus xylanexedens J155 and Bacillus cereus J156. Indole-3- acetic acid and ammonia were also produced by all strains, with a maxima of $204.28 \mu \mathrm{g} . \mathrm{mL}^{-1}$ in Bacillus megaterium $\mathrm{J11}$ and $0.33 \mu \mathrm{mol}^{\mathrm{mL}} \mathrm{m}^{-1}$ in Pseudomonas sp. J153, respectively. Pseudomonas sp. J10 and B. cereus J156 grew on plates containing 1500 $\mu \mathrm{g} \cdot \mathrm{mL}^{-1}$ of nickel nitrate, while Pseudomonas sp. $\mathrm{J} 153$ withstood $1500 \mu \mathrm{g} \cdot \mathrm{mL}^{-1}$ of either copper sulfate or cadmium sulfate. Phenotypic analysis of the potential of the isolates to promote early plant growth showed that wheat seeds inoculated with either $P$. moraviensis J12 or $B$. cereus $J 156$ remarkably increased germination rate and seedlings growth. Lastly, antibiotic resistance profiling revealed that except for Pseudomonas sp. J11 and $B$. cereus J156, remaining strains displayed resistance at least to one of tested antibiotics. Collectively, Pseudomonas sp. J10, P. moraviensis J12, Pseudomonas sp. J153 and B. cereus J156, represent potential biofertilizers suitable for soils that are poor in $\mathrm{P}$, and/or heavy metals contaminated. 


\title{
1 Phosphate solubilizing rhizobacteria isolated from
} 2 jujube Ziziphus lotus plant stimulate wheat germination 3 rate and seedlings growth

4

\author{
Nidal Fahsi ${ }^{1,2}$, Ismail Mahdi ${ }^{1,3}$, Abdelhalem Mesfioui $^{2}$, Latefa Biskri ${ }^{4,5}$, and Abdelmounaaim Allaoui ${ }^{4}$ \\ ${ }^{1}$ Medical Application Interface Center (CIAM), Mohammed VI Polytechnic University (UM6P), Benguérir, Morocco. \\ ${ }^{2}$ Laboratory of Biologie \& Santé, Faculty of Sciences, Ibn Tofail University, Kenitra, Morocco. \\ ${ }^{3}$ Laboratory of Microbial Biotechnologies, Agrobiosciences and Environement (BioMAgE), Faculty of Sciences \\ Semlalia, University Cadi Ayyad, 40000 Marrakesh, Morocco. \\ ${ }^{4}$ Molecular Microbiology laboratory, Coalition Center, for Innovation and Prevention of Epidemies in Morocco \\ (CIPEM), Mohammed VI Polytechnic University (UM6P) \\ ${ }^{5}$ African Genome Center (AGC), Mohammed VI Polytechnic University (UM6P) \\ Corresponding Author: abdelmounaaim.allaoui@um6p.ma \\ University Mohammed VI Polytechnic, Lot 660 - Hay Moulay Rachid, 43150 Ben Guerir, Morocco.
}

\section{Abstract}

Jujube plant (Ziziphus lotus (L.) Desf.) can survive in arid climates and tolerates both biotic and abiotic stresses. Here, we isolated, for the first time in Morocco, nine phosphate solubilizing bacteria strains from jujube rhizosphere, designated J10 to J13, J15, \& J153 to J156. Genotypic identification, based on $16 \mathrm{~S}$ rDNA sequencing, revealed six strains that belong to Pseudomonas (J10, J12, J13, J15, J153, J154), two to Bacillus (J11, J156), and one to Paenibacillus J155. Siderophores were produced by all strains. Proteases activity was missing in Pseudomonas sp. J153 \& J154, whereas cellulase was restricted only to Pseudomonas sp. J10, Paenibacillus xylanexedens $\mathrm{J} 155$ and Bacillus cereus J156. Indole-3- acetic acid and ammonia were also produced by all strains, with a maxima of $204.28 \mu \mathrm{g} \cdot \mathrm{mL}^{-1}$ in Bacillus megaterium $\mathrm{J} 11$ and 0.33 $\mu \mathrm{mol} . \mathrm{mL}^{-1}$ in Pseudomonas sp. J153, respectively. Pseudomonas sp. J10 and B. cereus J156 grew on plates containing $1500 \mu \mathrm{g} . \mathrm{mL}^{-1}$ of nickel nitrate, while Pseudomonas sp. J153 withstood 1500 $\mu \mathrm{g} . \mathrm{mL}^{-1}$ of either copper sulfate or cadmium sulfate. Phenotypic analysis of the potential of the isolates to promote early plant growth showed that wheat seeds inoculated with either $P$. moraviensis $\mathrm{J} 12$ or B. cereus $\mathrm{J} 156$ remarkably increased germination rate and seedlings growth. Lastly, antibiotic resistance profiling revealed that except for Pseudomonas sp. J11 and B. cereus J156, remaining strains displayed resistance at least to one of tested antibiotics. Collectively, Pseudomonas sp. J10, P. moraviensis J12, Pseudomonas sp. J153 and B. cereus J156, represent potential biofertilizers suitable for soils that are poor in $\mathrm{P}$, and/or heavy metals contaminated.

Subjects Soil Microbiology, Plant Bacteria Interaction, Plant Growth Promotion, Soil Biofertilization

Keywords Jujube plant, Plant growth promotion, Rhizobacteria, Phosphate solubilizing bacteria, Antibiotics resistance, Heavy metals tolerance, Wheat seeds germination 
44

45

46

47

48

49

50

51

52

53

54

55

56

57

58

59

60

61

62

63

64

65

66

67

68

69

70

71

72

73

74

75

76

77

78

79

80

81

82

83

\section{Introduction}

Phosphorus (P) is considered one of the most important elements in plant nutrition after nitrogen. It is an essential macronutrient to all major metabolic processes in plants growth e.g. photosynthesis, energy transfer, respiration, and signal transduction (Khan et al., 2010; Rahman et al., 2017). Phosphate solubilizing microorganisms including bacteria play an important role in enhancing soil fertility and plant growth (Miransari \& Mackenzie, 2010). Therefore, it is paramount to explore management strategies which are considered as an environmentally friendly process and economically feasible procedure to improve crop production and maximize their yields in P-poor soils (Zaidi et al., 2009). Exploration of the biodiversity of rhizobacteria and the optimization/manipulation of microbial interactions in the rhizosphere represents an imperative step towards formulating more efficient microbial inoculants with high P-solubilizing ability (Khan, Zaidi \& Wani, 2007). Although P is plentiful in soils in both organic and inorganic forms, it is in unavailable forms for root uptake (Sharma et al., 2013). Numerous soil microorganisms particularly those present in plant's rhizosphere can release the bound forms of $\mathrm{P}$ to a soluble form to increase its bioavailability to plants (Narayanasamy, Ghosh \& Sarkar, 1981; Dubey et al., 1997; Dave \& Patel, 2003). PSB (phosphate solubilizing bacteria) belong to plant growth promoting rhizobacteria (PGPR) and are capable of solubilizing inorganic P from a variety of sources, such as dicalcium phosphate, tricalcium phosphate, or rock phosphate (Khan et al., 2010). Rhizobacteria are considered to be the best-known beneficial plant-associated bacteria and the most valuable bioinoculants as they showed promising performances under controlled conditions such as the production of phytohormones, siderophores, phosphate solubilization, and nitrogen fixation (Pérez-Montaño et al., 2014).

A number of strategies have been documented to improve phosphorus availability in soils including, agronomic practices, organic amendments, composting, arbuscular mycorrhizal fungi, P efficient cultivars, and phosphate solubilizing microbes (Kunwar, Lamichhane \& Gauchan, 2018). This later strategy is one of the most promising, as it is more sustainable and considered to be eco-friendly (Gyaneshwar et al., 2002). In contrast to other strategies, microbes have multiples benefits to plants as they contribute directly and indirectly to the nutrition, biocontrol of pathogens, and mitigating abiotic stresses (Kunwar, Lamichhane \& Gauchan, 2018). Strains belonging to the bacterial genera Pseudomonas, Bacillus, Rhizobacterium, and Enterobacter are known as potent P solubilizing microorganisms (Whitelaw, 1999).

Antibiotic resistance is a major concern whose emergence and spreading rates are increasing. It is one of the major problems in deploying bacterial-based biofertilizers (Kang et al., 2017). Antibiotic resistance genes (ARGs) harbored by PGPB can be an inborn or gained property. Intrinsic resistance may be due to the presence of multidrug efflux pumps. This is supported by the phylogenetic analysis of several genes involved in antibiotic resistance which could be due to an evolutionary pattern (D'Costa et al., 2011; Van Goethem et al., 2018). Acquired antibiotic resistance may also reflect the acquisition of new resistance genes from other organisms by horizontal gene transfer from bacteria. The resistance of PGPR to antibiotics is a double-edged sword. On the one hand, resistant bacteria can serve either as markers to monitor bacteria survival 
84 in vitro or in vivo (Kluepfel, 1993; Trivedi et al., 2004), and to help them competing in native and

85

86

87

88

89

90

91

92

93

94

95

96

97

98

99

100

101

102

103

104

105

106

107

108

109

110

111

112

113

114

115

116

117

118

119

120

121

122 open microbial niches (Cray et al., 2013). On the other hand, their application in soil as bioinoculants may represent potential risks by transferring ARG to other bacteria colonizing the same environment (Ramakrishna, Yadav \& Li, 2019). However, a potential source of ARGs carried by PGPR and derived biocontrol agents and/or bio-fertilizers is widely forgotten and ignored (Kang et al., 2017). Hence, the urgency of large-scale introduction of the beneficial bacteria into soils can aggravate the situation leading to the spread of ARGs in the environment. In addition to antibiotic resistance, heavy metal pollution is an environmental concern that can have harmful effects on human health when they are taken up in amounts that cannot be processed by the organism (Chauhan \& Solanki, 2015). Many toxic elements such as $\mathrm{Cu}^{2+}, \mathrm{Pb}^{2+}, \mathrm{Zn}^{2+}, \mathrm{Cd}^{2+}$ and $\mathrm{As}^{3+}$ are generally found in detectable quantities in wastewater (Pescod, 1992). Some of these elements are necessary for plant growth, but a high concentration of them in wastewater becomes an obstacle (Pescod, 1992), which leads to the remediation of contaminated environments via sustainable methods (Pizarro-Tobias et al., 2015). Several methods are already being used to clean up the environment from these types of contaminants. The use of microorganisms capable of adsorbing heavy metal ions for bioremediation in contaminated soil is considered as an eco-friendly method and do not produce secondary pollution. Certain PGPR can reduce soil toxicity around plant roots. These PGPR also protect plants from being affected by toxic heavy metals (Gamalero \& Glick, 2011). Various free-living rhizospheric PGPR can be used in contaminated soils to alleviate lethal effects of heavy-metals (Belimov et al., 2004). Bacillus and Pseudomonas exhibit vital role in the bioremediation of heavy metals (Khan \& Ahmad, 2006; Niu et al., 2011).

The jujube tree (Ziziphus lotus (L.) Desf.) is a deciduous shrub belonging to the Rhamnaceae family. It is present in Morocco, in several biotopes of arid and semi-arid regions. It reaches 2 to $6 \mathrm{~m}$, with tightly branched stems and smaller flowers and fruits (Wang et al., 2016). It grows on all soils: limestone, siliceous, clayey, and sandy, without human intervention, and it supports small amounts of salt (Ionesco \& Sauvage, 1969). This shrub also behaves as a weed in several crops, including winter and spring cereals, food legumes and orchards in certain regions of Morocco such as Chaouia, Haouz, Zear, Rhamna and the Middle Atlas (Rsaissi \& Bencharki, 2012). It is considered as a multipurpose plant for arid and semi-arid areas where salt stress, drought, soil erosion and desertification (Chadha, 2001). In addition, jujube plant is traditionally used as sedative, bronchitis, antidiarrhea, skin infections, antiurinary troubles agents, antifever, insomnia agents, and hypoglycemic activities. These benefits are due to its richness in vitamins, polyphenols, amino acids, cyclopeptide alkaloids, minerals, and polyunsaturated fatty acids (Lahlou, El Mahi \& Hamamouchi, 2002; Adzu et al., 2003; Koley et al., 2016).

The characterization of jujube rhizospheric PSB and their effects on plant growth is poorly understood and have not been extensively studied yet. The omnipresence of PGPR microorganisms in nature especially in rhizospheres, and their exceptional ability to enhance plant growth led us to undertake the present study. We isolated, for the first time in Morocco, PSB from rhizospheric soil of jujube plants (Ziziphus lotus (L.) Desf.). We subsequently identified their genotype, assessed 
123 their conventional PGPR properties and tolerance to heavy metals and resistance to antibiotics in

124

125

126

127

128

129

130

131

132

133

134

135

136

137

138

139

140

141

142

143

144

145

146

147

148

149

150

151

152

153

154

155

156

157

158

159

160

161

vitro, and finally evaluated their effects on wheat seeds germination.

\section{Materials \& Methods}

\section{Sampling and bacterial isolation}

The sampling site, located in the experimental farm of Mohammed VI Polytechnic University (UM6P), Benguerir-Morocco $(32.219731 \mathrm{E},-7.892268 \mathrm{~N})$, is characterized by a temperate continental monsoon climate. The annual rainfall is $290,6 \mathrm{~mm}$ and mainly occurs from October to January. Eight samples of roots and rhizospheric soil of jujube were collected from a 5 to $25 \mathrm{~cm}$ depth, packed and labeled in sterile plastic bags, then transported immediately to the laboratory in cool boxes. Fractions from all soil samples were mixed and analyzed for some physicochemical properties at the Agricultural Innovation and Technology Transfer Center (AITTC) of UM6P. The results are shown in Table 1. Rhizospheric samples were serially diluted under aseptic conditions by suspending $1 \mathrm{~g}$ of rhizosphere soil in $9 \mathrm{~mL}$ of sterile deionized water. Next, $100 \mu \mathrm{L}$ of serial dilutions were subsequently plated on Tryptic Soy Agar medium (TSA) (EMD Millipore, Berlin, Germany) and incubated at $28 \pm 2{ }^{\circ} \mathrm{C}$ till the appearance of bacterial colonies. Screening of individual colonies was carried out by repeated streaking.

\section{Screening of phosphate solubilizing bacteria}

All bacterial isolates were qualitatively screened for inorganic P solubilization by inoculating a single colony of each strain in National Botanical Research Institute's Phosphate growth medium (NBRIP) containing 10 g.L - $^{-1}$ glucose; 0.1 g.L ${ }^{-1}(\mathrm{NH} 4)_{2} \mathrm{SO}_{4} ; 5$ g.L ${ }^{-1} \mathrm{MgCl}_{2} 6 \mathrm{H}_{2} \mathrm{O} ; 0.2$ g.L $\mathrm{L}^{-1} \mathrm{KCl}$, 0.25 g. $\mathrm{L}^{-1} \mathrm{MgSO}_{4}, 7 \mathrm{H}_{2} \mathrm{O}$ and finally 5 g.L $\mathrm{L}^{-1} \mathrm{Ca}_{3}\left(\mathrm{PO}_{4}\right)_{2}$ (TCP: insoluble tricalcium phosphate) as a sole source of phosphate (Nautiyal, 1999). The initial media $\mathrm{pH}$ was adjusted to 7.00 before use. Each bacterium was incubated on NBRIP plate at $30{ }^{\circ} \mathrm{C}$ for 7 days and only colonies surrounded by clear halos were selected for further studies as potential $\mathrm{P}$ solubilizer candidates. PSB were subsequently sub-cultured in TSB (Tryptic Soy Broth) (Professional lab, Casablanca, Morocco) liquid media and cryopreserved at $-80^{\circ} \mathrm{C}$ until use.

\section{Quantification of phosphate solubilization by bacteria}

Inorganic P-solubilizing activity was quantified using TCP (in a modified NBRIP liquid medium). Briefly, bacterial suspension $\left(0.1 \mathrm{~mL}\right.$ of $\left.\mathrm{OD}_{600 \mathrm{~nm}}=0,8\right)$ was inoculated in a $100 \mathrm{~mL}$ flask containing $50 \mathrm{~mL}$ of NBRIP broth in triplicate. Non-inoculated medium was used as blank, while Rhizobium tropici CIAT 899 served as a positive control. Bacterial cultures were incubated at 28 $\pm 2{ }^{\circ} \mathrm{C}$ during five days under shaking condition at $150 \mathrm{rpm}$. The cultures were then harvested by centrifugation at $13.000 \mathrm{rpm}$ for $10 \mathrm{~min}$ and the soluble $\mathrm{P}$, contained in the supernatant, was quantified by colorimetric method using SKALAR (SKALAR SAN++ SYSTEM). Dissolved P concentration was determined by subtracting the $\mathrm{P}$ concentration of the blank from the final concentration of soluble $\mathrm{P}$ in the inoculated broths. The final $\mathrm{pH}$ of each culture supernatant was 
162 also measured. The experiments were performed in triplicate and the results are means of the

163

164

165

166

167

168

169

170

171

172

173

174

175

176

177

178

179

180

181

182

183

184

185

186

187

188

189

190

191

192

193

194

195

196

197

198

199

200

201

replicates.

\section{Bacterial antibiotic resistance and heavy metal tolerance}

Antibiotic resistance profile of selected PSB was determined using TSA medium supplemented with selected antibiotics namely kanamycin $\left(50 \mu \mathrm{g} \cdot \mathrm{mL}^{-1}\right)$, streptomycin $\left(100 \mu \mathrm{g} \cdot \mathrm{mL}^{-1}\right)$, tetracycline $\left(10 \mu \mathrm{g} \cdot \mathrm{mL}^{-1}\right)$, ampicillin $\left(100 \mu \mathrm{g} \cdot \mathrm{mL}^{-1}\right)$, chloramphenicol $\left(20 \mu \mathrm{g} \cdot \mathrm{mL}^{-1}\right)$ and spectinomycin $\left(60 \mu \mathrm{g} \cdot \mathrm{mL}^{-1}\right)$.

Heavy metal tolerance of selected isolates was tested using the same method (TSA plates) with the addition of increasing concentrations (ranging from 0 to $1500 \mu \mathrm{g} \cdot \mathrm{mL}^{-1}$ ) of three heavy metals; cadmium sulfate $\left(\mathrm{CdSO}_{4}\right)$, copper sulfate $\left(\mathrm{CuSO}_{4} \cdot 5 \mathrm{H}_{2} \mathrm{O}\right)$ and nickel nitrate $\left(\mathrm{N}_{2} \mathrm{NiO}_{6}\right)$. The plates were incubated at $30^{\circ} \mathrm{C}$ for $24 \mathrm{~h}$.

\section{Strains genotyping using 16S rRNA gene sequencing}

PSB identification was performed using 16S rRNA gene sequencing. The polymerase chain reactions (PCR) were carried out directly with fresh bacterial suspension, using a pair of universal primers pA (5'- AGAGTTTGATCCTGGCTCAG-3') and 926R_Quince (degenerated one) (5'CCG YCAATTYMTTTRAGTTT-3'), and MyTaq Mix, 2X (ThermoFisher, Casablanca, Morocco) containing Taq DNA polymerase, $\mathrm{dNTP}, \mathrm{MgCl}_{2}$ and buffer. Amplification of $16 \mathrm{~S}$ rDNA sequences was made in $50 \mu \mathrm{l}$ reaction mixture containing $25 \mu \mathrm{L}$ of MyTaq mix, $1 \mu \mathrm{L}$ of each primer $(20 \mu \mathrm{M}), 22 \mu \mathrm{L}$ of DNase/RNase-free distilled water and $1 \mu \mathrm{L}$ of overnight bacterial culture as DNA template. The reaction was performed in a VWR ${ }^{\circledR}$ thermal cycler using the following PCR optimized conditions: initial denaturation at $95{ }^{\circ} \mathrm{C}$ for $5 \mathrm{~min}, 35$ cycles of denaturation at 95 ${ }^{\circ} \mathrm{C}$ for $30 \mathrm{~s}$, annealing at $52{ }^{\circ} \mathrm{C}$ for $30 \mathrm{~s}$, elongation at $72{ }^{\circ} \mathrm{C}$ for $1 \mathrm{~min}$, and final elongation at 72 ${ }^{\circ} \mathrm{C}$ during $10 \mathrm{~min}$. The amplified 16S rDNA fragments (910-bp) were sequenced by Genome Quebec, Canada. The generated DNA sequences were aligned to available standard sequences of bacterial lineage in the National Center for Biotechnology Information GenBank database (http://www.ncbi.nlm.nih.gov/) and the High-Quality Ribosomal RNA databases SILVA (https://www.arb-silva.de) using BLAST algorithm to carry out a taxonomic assignment of each isolate. The phylogenetic tree of identified PSB was built using Ugene software.

\section{Indole-3- acetic acid (IAA) measurement assay}

Bacteria were analyzed for the quantitative determination of indole acetic acid (IAA) production. For this purpose, $100 \mu \mathrm{L}$ of each PSB strain $\left(\mathrm{OD}_{600 \mathrm{~nm}}=0.8\right)$ was grown in $50 \mathrm{~mL}$ Tryptic Soy Broth (TBS) supplemented with $0.1 \%$ L-tryptophan as IAA precursor at $28 \pm 2{ }^{\circ} \mathrm{C}$ in a shaking incubator at $200 \mathrm{rpm}$. After 7 days, $2 \mathrm{~mL}$ of Salkowski reagent $\left[0.5 \mathrm{M} \mathrm{FeCl}_{3}: 70 \%\right.$ perchloric acid/water (2:49:49 ratio)] (Glickmann \& Dessaux, 1995), was pipetted into test tubes containing $1 \mathrm{~mL}$ of culture supernatant filtrates. The tubes containing the mixture were gently vortexed and left for $30 \mathrm{~min}$ in dark for the development of color at room temperature $\left(26 \pm 2^{\circ} \mathrm{C}\right)$. The absorbance was determined at an $\mathrm{OD}_{535} \mathrm{~nm}$. The quantity of IAA produced in each supernatant was 
202 estimated in $\left(\mu \mathrm{g} . \mathrm{mL}^{-1}\right)$ from a calibration curve using a standard IAA (Sigma Aldrich, Overijse, 203 Belgium).

204

205

206

207

208

209

210

211

212

213

214

215

216

217

218

219

220

221

222

223

224

225

226

227

228

229

230

231

232

233

234

235

236

237

238

239

240

241

\section{Siderophores production assay}

Qualitative production of siderophores by selected strains was detected on the chrome-azurol S (CAS) medium as previously described (Schwyn \& Neilands, 1987). Briefly, each bacterial culture was spot-inoculated separately on CAS agar plates. The plates were kept at $30^{\circ} \mathrm{C}$ for 3 days. After the incubation period, the appearance of orange halo (blue to yellow/orange) around the colony was considered as a positive result for siderophores production.

\section{Extracellular enzymes production assay}

Bacteria were qualitatively analyzed for the production of protease and cellulase by the plate method (Kavitha, Nelson \& Jesi, 2013). Protease activity (casein degradation) was tested by inoculation of selected strains into nutrient agar medium containing casein 5 g.L. $\mathrm{L}^{-1}$, yeast extract 2.5 g.L ${ }^{-1}$, glucose 1 g.L $\mathrm{L}^{-1}$, and agar 15 g.L $\mathrm{L}^{-1}$ and amended with $10 \%$ of skim milk. After $48 \mathrm{~h}$ incubation at $30{ }^{\circ} \mathrm{C}$, a clear zone around colonies indicated positive proteolytic activity. For cellulase activity, a mineral-salt agar plate containing $0.4 \%\left(\mathrm{NH}_{4}\right)_{2} \mathrm{SO}_{4}, 0.6 \% \mathrm{NaCl}, 0.1 \%$ $\mathrm{K}_{2} \mathrm{HPO}_{4}, 0.01 \% \mathrm{MgSO}_{4}, 0.01 \% \mathrm{CaCl}_{2}$ with $0.5 \%$ carboxymethyl cellulose, and $2 \%$ agar were surface-inoculated with each strain and incubated $48 \mathrm{~h}$ at $30{ }^{\circ} \mathrm{C}$. Plates were stained with $0.1 \%$ Congo Red (Sigma Aldrich, Casablanca, Morocco) for 15 min. Following de-staining during 15 min, using $1 \mathrm{M} \mathrm{NaCl}$, the development of the halo zone around the colonies reflects cellulase production.

\section{Ammonia production assay}

Bacteria strains were tested, qualitatively and quantitatively, for ammonia production in peptone water as previously described (Cappuccino \& Sherman, 1992). Briefly, freshly grown cultures were inoculated into $10 \mathrm{~mL}$ peptone water and incubated for $48 \mathrm{~h}$ at $30{ }^{\circ} \mathrm{C}$ on a shaker $(150 \mathrm{rpm})$. Post incubation period, $0.5 \mathrm{~mL}$ of Nessler's reagent was added to each tube. Ammonia production is proportional to the brown color intensity. It was measured spectrophotometrically at $\mathrm{OD}_{450 \mathrm{~nm}}$ using the VICTOR NivoTM Multimode Plate Reader (PerkinElmer, Casablanca, Morocco) and determined using a standard curve prepared with $0.1-1 \mu \mathrm{mol} . \mathrm{mL}^{-1}$ ammonium sulfate.

\section{Wheat seeds germination assay}

Our selected strains were assessed for their effect on seed germination. Seeds of durum wheat (Variety vitron) were surface sterilized with $2 \%$ sodium hypochlorite solution for $1 \mathrm{~min}$, rinsed thoroughly with sterile distilled water, soaked in 70\% ethanol for $1 \mathrm{~min}$ and washed 5 times in single distilled water followed by air-drying. PSB cell pellets were obtained by centrifuging an overnight culture $\left(\mathrm{OD}_{600 \mathrm{~nm}}=0,8\right)$ at $10.000 \mathrm{rpm}$ for $5 \mathrm{~min}$, the supernatant was removed, and the pellets were resuspended in $5 \mathrm{~mL}$ of sterile distilled water, vortexed and used for seed treatment. Fifteen sterilized seeds were treated with $5 \mathrm{~mL}$ of bacterial suspension for $30 \mathrm{~min}$, air-dried, and 
242 then placed on sterile Petri dishes containing $0.7 \%$ agar medium and incubated at $25^{\circ} \mathrm{C}$. Triplicates

243 were maintained for each treatment. Seeds were surface sterilized with $2 \%$ sodium hypochlorite 244 solution for $1 \mathrm{~min}$, rinsed thoroughly with sterile distilled water. Next, seeds were incubated in a 245 dark incubator for $48 \mathrm{~h}$, then left at room temperature in a day/night cycle. The germination rate 246 was recorded after $24 \mathrm{~h}$ and $48 \mathrm{~h}$. Root length, shoot length, fresh weight, and dry weight were 247 measured after 7 days. The germination rate and vigor index were calculated using the following 248 formula (Islam et al., 2016):

249

250

251

252

253

254

255

256

257

258

259

260

261

262

263

264

265

266

267

268

269

270

271

272

273

274

275

276

277

278

279

280

$$
\text { Vigor index }=\% \text { Germination } \times \text { Total plant lenght }
$$

\section{Statistical analysis}

Results presented here are the mean of triplicates $(n=3) \pm$ Standard deviation. Statistical analysis was performed using IBM SPSS statistics 20 for windows. The differences between treatments were statistically analyzed using analysis of variance (ANOVA) and subsequently by Tukey's multiple range test at $\mathrm{p}<0.05$.

\section{Results}

\section{Bacteria screening identified nine best phosphate solubilizing strains}

The screening of $\mathrm{P}$ solubilizing bacteria from different rhizospheric soil samples of jujube on NBRIP led to the isolation of forty-one bacterial isolates. This microbial population has different aspects, but all exhibited a common character of tricalcium phosphate $\left(\mathrm{Ca}_{3}\left(\mathrm{PO}_{4}\right)_{2}\right)$ solubilization on solid medium. Indeed, bacterial isolates were able to form a clear zone (halo) around their colonies on the NBRIP medium, indicating positive solubilization of $\mathrm{P}$ from tricalcium phosphate (TCP). Nine isolates were selected as being the best performers on plates and named J10 to J13, $\mathrm{J} 15$, and $\mathrm{J} 153$ to $\mathrm{J} 156$ (J for Jujube). Next, we tested their ability to solubilize inorganic phosphorus $\left(\mathrm{Ca}_{3}\left(\mathrm{PO}_{4}\right)_{2}\right)$ in NBRIP liquid medium. The amount of soluble $\mathrm{P}$ and growth media's $\mathrm{pH}$ were measured 5 days post incubation. Eight strains were found to release $\mathrm{P}$ from TCP with concentrations ranging from $20.5 \mathrm{mg} \cdot \mathrm{L}^{-1}$ to $264 \mathrm{mg} \cdot \mathrm{L}^{-1}$ (Fig. 1). Remarkably, the highest solubilization was recorded for strain $\mathrm{J} 153$, while the lowest one $\left(20.5 \mathrm{mg} . \mathrm{L}^{-1}\right)$ was measured for strain J11. The amount of P solubilization by the referenced strain, Rhizobium tropici did not exceed $67.5 \mathrm{mg} . \mathrm{L}^{-1}$. As expected, $\mathrm{P}$ solubilization was accompanied by a significant drop in $\mathrm{pH}$, of the culture media, from 7.0 to 4.0 (Fig. 1).

Strains J10-13, J15 and J153-156 belong to the genera of Pseudomonas, Bacillus, and Paenibacillus

Characterization of the nine PBS strains to the genus level was performed by $16 \mathrm{~S}$ ribosomal DNA gene partial sequencing. Generated sequences of 900-bp length were aligned to available $16 \mathrm{~S}$ 
281

282

283

284

285

286

287

288

289

290

291

292

293

294

295

296

297

298

299

300

301

302

303

304

305

306

307

308

309

310

311

312

313

314

315

316

317

318

319

320

321

rDNA sequences using GenBank and SILVA databases. As summarized in Table 2, three strains (J12, J13, and J15) show 98\% identity to the 16S rRNA gene sequences of Pseudomonas moraviensis; three strains J10, J153, and J154 share 98-99\% identity to Pseudomonas sp.; two strains J11 and J156 exhibit 98 and 99\% identity to Bacillus megaterium and Bacillus cereus, respectively. Lastly strain J155 shares 98\% identity to Paenibacillus xylanexedens (Fig. 2).

Except for Pseudomonas sp. J11 and B. cereus J156, remaining strains displayed resistance at least to one antibiotic

PGPB tend to harbor genes that confer resistance to antibiotics (Kang et al., 2017). To assess bacterial resistance to antibiotics, we checked our strains for growth on plates supplemented with a set of different antibiotics, frequently encountered among bacteria isolated from soils. As reported in Table 3, out of the nine tested strains, seven presented resistance at least to one antibiotic. Strains P. moraviensis J12 \& J15, Pseudomonas sp. J153 \& J154 resist to chloramphenicol and ampicillin, while Pseudomonas sp. J10 \& J13 confer resistance to chloramphenicol, ampicillin, and spectinomycin. Strains Pseudomonas sp. J11 and Bacillus cereus J156 are sensitive to all tested antibiotics. Strain P. xylanexedens J155 is resistant to both kanamycin and spectinomycin. Lastly, none of the tested strains are resistant to neither streptomycin nor tetracycline (Table 3). In the next steps, to avoid any potential contamination, we took advantage to these resistances to grow bacteria on selective media.

\section{Pseudomonas sp. $\mathrm{J} 153$ and $B$. cereus $\mathrm{J} 156$ withstand high concentrations of copper sulfate/cadmium sulfate and copper sulfate/nickel nitrate, respectively}

Heavy metals such as lead $(\mathrm{Pb})$, cadmium $(\mathrm{Cd})$, chromium $(\mathrm{Cr})$, and mercury $(\mathrm{Hg})$ are exceptionally toxic and dangerous environmental pollutants (Tangahu et al., 2011). We investigated the capacity of our strains to grow under various concentrations of nickel nitrate $\left(\mathrm{N}_{2} \mathrm{NiO}_{6}\right)$, copper sulfate pentahydrate $\left(\mathrm{CuSO}_{4} .5 \mathrm{H}_{2} \mathrm{O}\right)$ and cadmium sulfate $\left(\mathrm{CdSO}_{4}\right)$. The nine strains exhibited various tolerance characteristics (Table 4). In the copper assay, Pseudomonas sp. $\mathrm{J} 153$ grows up to $1500 \mu \mathrm{g} \cdot \mathrm{mL}^{-1}$, Bacillus cereus $\mathrm{J} 156$ to $1000 \mu \mathrm{g} . \mathrm{mL}^{-1}$, while strains Pseudomonas sp. $\mathrm{J} 10$, P. moraviensis $\mathrm{J} 12$, P. moraviensis $\mathrm{J} 13$, and $P$. moraviensis $\mathrm{J} 15$ supported a maximum of $500 \mu \mathrm{g} \cdot \mathrm{mL}^{-1}$. The lowest tolerated concentration, 300 and $200 \mu \mathrm{g} . \mathrm{mL}^{-1}$ were seen in B. megaterium J11 and Pseudomonas sp. J154 strains, respectively. When tested for cadmium sulfate, only Pseudomonas sp. J153 grows up to $1500 \mu \mathrm{g} \cdot \mathrm{mL}^{-1}$, whereas $300 \mu \mathrm{g} \cdot \mathrm{mL}^{-1}$ was the maximal concentration tolerated by strains Pseudomonas sp. J10, P. moraviensis J12, P. moraviensis J13, P. moraviensis $\mathrm{J} 15$, Pseudomonas $\mathrm{sp} . \mathrm{J} 154$ and B. cereus $\mathrm{J} 156$. Lastly, low tolerance at $100 \mu \mathrm{g} . \mathrm{mL}^{-}$ 1 and $10 \mu \mathrm{g} \cdot \mathrm{mL}^{-1}$ were detected in strains $P$. xylanexedens $\mathrm{J} 155$ and B. megaterium $\mathrm{J} 11$, respectively (Table 4). In the nickel nitrate assay, Pseudomonas sp. J10 and Bacillus cereus J156 strains, grow up to $1500 \mu \mathrm{g} \cdot \mathrm{mL}^{-1}$ and strain $P$. xylanexedens $\mathrm{J} 155$ tolerated the lowest concentration of $300 \mu \mathrm{g} \cdot \mathrm{mL}^{-1}$. However, the remaining strains tolerate growth up to $500 \mu \mathrm{g} \cdot \mathrm{mL}^{-1}$. Taking together, our data highlighted the remarkable capacity of strains Pseudomonas sp. J153 and $B$. cereus J156 to withstand abnormal high concentrations of both copper sulfate/cadmium sulfate and copper sulfate/nickel nitrate, respectively.

Peer) reviewing PDF | (2021:01:57105:2:1:NEW 17 May 2021) 
323

324

325

326

327

328

329

330

331

332

333

334

335

336

337

338

339

340

341

342

343

344

345

346

347

348

349

350

351

352

353

354

355

356

357

358

359

360

361

\section{B. megaterium $\mathrm{J11}$ is the best indole-3-acetic acid producer}

The production of indole acetic acid (IAA) is a major property shared by numerous rhizospheric bacteria that stimulate plant growth (Mohite, 2013). Seven days post incubation, all tested strains produced IAA although at various levels, ranging from 57.1 to $204.28 \mu \mathrm{g} \cdot \mathrm{mL}^{-1}$ (Fig. 3). The highest concentration was produced by $B$. megaterium $\mathrm{J} 11$, whereas the lowest one was measured for P. xylanexedens J155 (Fig. 3).

\section{$P$. moraviensis $\mathrm{J13}$ is the best siderophores producer}

Siderophores are best known for binding iron (Fe) and for mobilizing soil-immobilized Fe, although they may also contribute to improve the availability of P to plants (Sharma et al., 2013), by solubilizing minerals and chelating heavy metals, which in turn increases nutrient uptake and plant growth (Gontia-Mishra et al., 2016). The ability, in vitro, of selected PSB, to produce siderophores was qualitatively estimated using the CAS-agar plate assay. All tested strains were able to produce siderophores, although at various levels as deduced by the size of the halo zone and the intensity of the color change of the CAS-Agar (Table 3). P. moraviensis J13 was the most efficient siderophores producer, the six strains (Pseudomonas sp. J10, J153 \&J154, P. moraviensis $\mathrm{J} 12$ \& J15, and $P$. xylanexedens $\mathrm{J} 155$ produced intermediate level, whereas the lowest production was seen in both B. megaterium $\mathrm{J} 11$ and $B$. cereus $\mathrm{J} 156$ strains.

\section{Pseudomonas sp. J153 is the best ammonia producer}

Ammonia is a chemical compound having indirect plant health benefits, primarily by acting as metabolic inhibitor against phytopathogens(Kumar et al., 2012). All tested strains were able to produce ammonia with various concentrations. The highest value of $0.33 \mu \mathrm{mol} . \mathrm{mL}^{-1}$ was detected in Pseudomonas sp. J153, while the lowest one, $0.1 \mu$ mol. $\mathrm{mL}^{-1}$, was measured in P. xylanexedens J155 (Fig. 4).

\section{Proteases are not produced by Pseudomonas sp. J153 and $\mathrm{J} 154$ and cellulase activity is} restricted to Pseudomonas sp. J10, J155 and B. cereus J156

Bacterial extracellular enzymes such as proteases and cellulases play a dual important role in the biological control of phytopathogens and in soil fertilization (Mitchell \& Alexander, 1963). The nine strains were tested for their ability to produce proteases and cellulases. Results of both proteases and cellulase assay are shown in Table 3. As for proteases production, except for Pseudomonas sp. J153 \& J154, the remaining seven strains developed halo zone around the colonies. As a control, no halo zone was seen using E. coli strain DH5 $\alpha$, used here as a negative control. Cellulase activity was solely detected in three strains: Pseudomonas sp. J10, $P$. xylanexedens $\mathrm{J} 155$, and $B$. cereus $\mathrm{J} 156$, each of which formed a yellow/whitish zone around their colonies and were considered as cellulase positive. No cellulase activity was observed in the remaining six other strains.

Peer) reviewing PDF | (2021:01:57105:2:1:NEW 17 May 2021) 
362

363

364

365

366

367

368

369

370

371

372

373

374

375

376

377

378

379

380

381

382

383

384

385

386

387

388

389

390

391

392

393

394

395

396

397

398

399

400

401

Inoculation with $P$. moraviensis $\mathrm{J} 12$ and $B$. cereus $\mathrm{J} 156$ promote the highest rate of wheat seeds germination and seedlings growth

The treatment of wheat seeds by the nine PSB strains had a significant effect $(\mathrm{P}<0.05)$ on the germination rate and wheat vigor index, as compared to the control (Fig. $5 \mathrm{~A}$ et E). However, these effects varied depending on the PSB isolates. For instance, both P. moraviensis $\mathrm{J} 12$ and B. cereus $\mathrm{J} 156$ strains were the most efficient in promoting wheat germination as represented by vigor index (Figure $5 \mathrm{E}$ ). Results revealed that, compared to non-inoculated control, seeds inoculated by each of the nine strains showed a considerable impact on different growth parameters (Fig. 6).

Regarding shoot and root length after 7 days of growth, seeds inoculated with all strains, especially B. megaterium J11 significantly enhanced shoot and root length $(\mathrm{p}<0.05)$. Maximum root length was seen upon inoculation with P. moraviensis J12 (Fig. 5 B). We also noticed, whatever the nature of the inoculum was, seeds root dry weights remain unchanged. In contrast, a significant increase in shoot dry weight was detected (Fig. 5 D). Furthermore, wheat seeds inoculation significantly affected shoot fresh weight, but not root dry weight except for $B$. megaterium $\mathrm{J} 11$, P. moraviensis $\mathrm{J} 12$, and $\mathrm{J} 15$ strains (Fig. 5 C).

\section{Discussion}

Phosphorus is an important limiting factor in agriculture production and microbial P solubilization seems to be an effective process to release the precipitated $\mathrm{P}$ in soil. In the present work, we isolated and screened nine P solubilizing bacteria from Jujube roots. Genotyping analysis revealed that these strains belong to the genera of Pseudomonas, Bacillus, and Paenibacillus. A recent study based on ACC-deaminase-producing screening criteria, reported that Pseudomonas and Bacillus genus are among species that are associated with jujube rhizospheric plant with the dominance of Pseudomonas genus (Zhang et al., 2020). Our isolated bacteria were characterized as being P solubilizers with values ranging from 20.5 to $264 \mathrm{mg} . \mathrm{L}^{-1}$. Comparatively, Zhang et al., (2020), reported that Pseudomonas lini (KM349410) isolated from jujube rhizosphere, was the best $\mathrm{P}$ solubilizing strain at $69 \mathrm{mg} . \mathrm{L}^{-1}$. We found here that the highest concentration of dissolved $\mathrm{P}$ in the medium was recorded by genus Pseudomonas followed by Paenibacillus, and then by our two Bacillus strains. Not surprisingly given, the $\mathrm{pH}$ of all bacterial cultures dropped significantly from 7.0 to 4.0, likely due of organic acids production (Pandey \& Maheshwari, 2007; Khan, Zaidi \& Ahmad, 2014; Otieno et al., 2015). Indeed, different genera of bacteria uses multiple P solubilization mechanisms, in addition to the production of acids, such as chelation and siderophores (Pandey \& Maheshwari, 2007).

Indole-3-acetic acid has been associated with plant growth promoting effect of several rhizospheric microorganisms that stimulate elongation and proliferation of root systems (Glick, 2012; Shilev, 2013; Otieno et al., 2015; Thomas, Murphy \& Murray, 2016; Mazumdar, Saha \& Ghosh, 2019). IAA is also frequently used as a marker to select beneficial bacteria (Went \& Thimann, 1937). Auxin production stimulates root development resulting in a higher nutrients and water absorption from the soil (Höflich, Wiehe \& Kühn, 1994). B. megaterium J11 is the best IAA producer $\left(204.28 \mu \mathrm{g} . \mathrm{mL}^{-1}\right)$, and the lowest in-term of $\mathrm{P}$ solubilization $\left(20.5 \mathrm{mg} \cdot \mathrm{L}^{-1}\right)$, but

Peer) reviewing PDF | (2021:01:57105:2:1:NEW 17 May 2021) 
402 significantly stimulates wheat seedling. Recent genome sequencing of Bacillus megaterium TRQ8 403 isolated from wheat (Triticum turgidum subsp. durum) rhizosphere, revealed the presence of genes 404 specifying factors associated with bacteria-plant interactions, i.e., auxin biosynthesis (indoles), 405 phosphate metabolism, siderophores production, and osmotic/oxidative stress response (Montoya, 406 Cota \& de los Santos Villalobos, 2019).

407 Our isolated strains produced various levels of siderophores but $P$. moraviensis J13 was the 408

409

410

411

412

413

414

415

416

417

418

419

420

421

422

423

424

425

426

427

428

429

430

431

432

433

434

435

436

437

438

439

440

441 best producer. During plant-bacteria association, siderophores production is beneficial to plant and are considered as an important trait of PGPR (Bal et al., 2013), that may influence plant growth as they mobilize different metal ions and play also an important role in bio-control (Matthijs et al., 2007). The $P$. moraviensis strain J12 exhibits a good production of siderophores in addition to be the highest $\mathrm{P}$ solubilizer, promotes shoot and root length, root fresh weight and stimulates wheat seeds germination. Compared to $P$. moraviensis $\mathrm{J} 13$, strain $P$. moraviensis $\mathrm{J} 12$ increases root fresh weight. The third strain of $P$. moraviensis $\mathrm{J} 15$ increases root and shoot length, shoot dry weight and stimulates wheat seedling.

Ammonia production is an essential PGPR trait often associated with plant growth (Yadav, Verma \& Tiwari, 2010). We found that Pseudomonas sp. J153 is the best ammonia producer. Remarkably, both Pseudomonas sp. J153 and J154 strains are lacking both proteases and cellulase activities, usually required to degrade the cell walls of phytopathogens (Hameeda et al., 2008; Nagpure, Choudhary \& Gupta, 2014). These activities are required during plant-microbe interactions and in roots intercellular colonization ( $M a$ et al., 2011). The cellulase activity was restricted only to Pseudomonas sp. J10, B. cereus J156 and P. xylanexedens J155. Despite that $P$. xylanexedens $\mathrm{J} 155$ is the lowest in terms of IAA and ammonia production and only intermediate in term of $\mathrm{P}$ solubilization, it stimulates wheat seedling, root and shoot development. This finding is in-lane with a report showing that Paenibacillus significantly increased both dry and fresh weight of inoculated wheat (Zhao et al., 2015). Interestingly, B. cereus J156 strain promotes wheat germination, seedlings growth, shoot length, shoot dry weight and seedling vigor index, a finding in-line with other studies (Raju et al., 1999; Raj et al., 2003; Raj, Shetty \& Shetty, 2004; Kamran, Shazia \& Shahida, 2010), in which Triticum aestivum's seeds germination was increased following inoculation with either Pseudomonas or Bacillus strain (Kamran, Shazia \& Shahida, 2010; Bal et al., 2013).

As the soil is a heterogeneous habitat and represents a broad spectrum of different ecological niches, it is well admitted that bacterial resistance to antibiotics facilitates their survival among the microbiome communities. Except for B. megaterium strain J11 and B. cereus J156, all other strains were resistant towards at least one of the six tested antibiotics. Soils are important reservoirs of diverse antibiotic resistance genes that can increase rapidly in clinical settings through horizontal gene transfer. Therefore, agricultural soils could play a major role in antibiotic resistance transmission. Additionally, a previous report has provided evidence for the exchanges of antibiotic resistance genes between soil (environmental) bacteria and clinical pathogens (Ramakrishna, Yadav \& $L i$, 2019). To enable a sustainable agriculture and an effective antibiotic policy, it become necessary to unravel the conditions modulating the abundance of resistance genes in their 
442 microbial environment (Kang et al., 2017). Based on our results, and to avoid future use of bacteria 443 conferring multi-resistance to antibiotics, the two bacillus strains B. megaterium $\mathrm{J} 11$ and B. cereus $444 \mathrm{~J} 156$ that are sensitive to antibiotics, may represent potential safer use as biostimulants candidates. 445 Here, we also addressed the capacity of our strains to grow under increasing concentrations of 446 heavy metals such as cadmium sulfate, nickel nitrate and copper sulfate. Pollution by heavy metals 447 is considered as the main contaminants of our food supply, especially crop production (Chauhan $448 \&$ Chauhan, 2014). Contamination of plants occurs through the absorption of heavy metals from 449 the soil, air, and water (Sharma, Agrawal \& Marshall, 2008; Singh et al., 2010). Consequently,

450

451

452

453

454

455

456

457

458

459

460

461

462

463

464

465

466

467

468

469

470

471

472

473

474

475

476

477

478

479

480

481 several adverse effects due to heavy metals pollution are considered as a great concern to public health, environmental health, and agricultural production (Fergusson, 1990; Msaky \& Calvet, 1990; Ma et al., 1994; Goyer, 1997). Compared to literature (Chauhan \& Solanki, 2015), our strains Pseudomonas sp. J10, B.cereus J156, and Pseudomonas sp. J153 tolerate higher concentration of heavy metals. The ability to adapt to heavy metal stress by developing various resistance mechanisms is partly mediated by bacteria production of intracellular metal binding proteins (Hashem \& Abed, 2002). Both Pseudomonas sp. J10 and B. cereus J156 exhibit an adaptive response against nickel nitrate at $1500 \mu \mathrm{g} . \mathrm{mL}^{-1}$ whereas Pseudomonas sp. J153 tolerated up to $1500 \mu \mathrm{g} \cdot \mathrm{mL}^{-1}$ of either copper sulfate or cadmium sulfate. Moreover, these values are remarkably high compared to $200 \mu \mathrm{g} \cdot \mathrm{mL}^{-1}$ defined as the minimal inhibitory concentration of $\mathrm{Cd}$ and $\mathrm{Ni}$ in relation to previously isolated soil-bacteria (Chauhan \& Solanki, 2015). However a recent study reported that Bacillus cereus tolerates up to $1500 \mu \mathrm{g} \cdot \mathrm{mL}^{-1}$ of cadmium sulfate (Khan et al., 2018). Collectively, it appears clearly that Pseudomonas sp. J10 \& J153 and B. cereus J156 strains possess the ability to withstand higher concentrations of heavy metals. Therefore, they are potential candidates suitable as bioremediatory agents for contaminated soils.

\section{Conclusions}

The present study aimed to isolate and to characterize PSB isolated from the jujube plant (Ziziphus lotus (L.) Desf.). Among the nine tested strains, Pseudomonas sp. J12 and Bacillus cereus J156, emerged as potential bioinoculants as they share multiple beneficial conventional PGP traits and promote seedlings wheat growth. In addition to Bacillus cereus J156, strains Pseudomonas sp. J10 and J153 emerged as potential candidates suitable to bioremediate heavy metals contaminated soils. To our knowledge, these results represent the first report on Ziziphus lotus (L.) Desf. associated PSB in Morocco and their role in promoting plant growth and alleviating heavy metals contamination. Here, we propose the use of the four promising strains Pseudomonas sp. J10, $P$. moraviensis J12, Pseudomonas sp. J153 and B. cereus J156, either for soil fertilization or heavy metals toxicity alleviation. Nevertheless, future agronomic studies on the field, using various plants, are required to explore elected bacterial strains' dual role in biofertilization and in the bioremediation processes.

\section{ADDITIONAL INFORMATION AND DECLARATIONS}

Peer) reviewing PDF | (2021:01:57105:2:1:NEW 17 May 2021) 
483 Funding.

484 This work was supported by a welcome grant from the University Mohammed VI Polytechnic

485 UM6P.

486

\section{Competing Interests}

488 The authors declare there are no competing interests.

489

490

\section{Author Contributions}

491 Nidal Fahsi designed and performed the experiments, analyzed the data, and wrote the first draft 492 of the paper and drawed figures and tables.

493 Ismail Mahdi designed and performed some experiments and analyzed the data.

494 Abdelhalem Mesfioui supervised the administrative Nidal Fahsi thesis' work.

495 Latefa Biskri conceived the experiments, authored and reviewed drafts of the paper.

496 Abdelmounaaim Allaoui authored and reviewed drafts of the paper and approved the final draft.

497

498

\section{Acknowledgements.}

499 We thank Mohamed Hijri for helpful discussions and facilities.

500

501

\section{References}

502 Adzu B, Amos S, Amizan M, Gamaniel K. 2003. Evaluation of the antidiarrhoeal effects of 503 Zizyphus spina-christi stem bark in rats. Acta tropica 87:245-250.

504 Bal HB, Das S, Dangar TK, Adhya TK. 2013. ACC deaminase and IAA producing growth

505 promoting bacteria from the rhizosphere soil of tropical rice plants. Journal of basic microbiology 506 53:972-984.

507 Belimov A, Kunakova A, Safronova V, Stepanok V, Yudkin LY, Alekseev YV, Kozhemyakov A. 508 2004. Employment of rhizobacteria for the inoculation of barley plants cultivated in soil 509 contaminated with lead and cadmium. Microbiology 73:99-106.

510 Cappuccino J, Sherman N. 1992. Microbiology: A laboratory manual (pp. 125-179). New York.

511 Chadha K. 2001. Handbook of horticulture. Handbook of horticulture.

512 Chauhan G, Chauhan U. 2014. Human health risk assessment of heavy metals via dietary intake

513 of vegetables grown in wastewater irrigated area of Rewa, India. International journal of scientific 514 and research publications 4:1-9.

515 Chauhan M, Solanki M. 2015. Isolation of cadmium resistant bacteria for environmental clean-up.

516 Int J Pharm Res 7:29-33.

517 Cray JA, Bell AN, Bhaganna P, Mswaka AY, Timson DJ, Hallsworth JE. 2013. The biology of

518 habitat dominance; can microbes behave as weeds? Microbial biotechnology 6:453-492.

519 Dave A, Patel H. 2003. Impact of different carbon and nitrogen sources on phosphate solubilization 520 by Pseudomonas fluorescens. Indian Journal of Microbiology 43:33-36.

521 D’Costa VM, King CE, Kalan L, Morar M, Sung WW, Schwarz C, Froese D, Zazula G, Calmels 
522 F, Debruyne R. 2011. Antibiotic resistance is ancient. Nature 477:457-461.

523 Dubey S, Balasundaram V, Pant L, Jayasheela N, Kawale B, Mishra B. 1997. Effect of phosphate

524 dissolving bacteria applied with rock phosphate on nodulation and yield of rainfed soybean under

525 different agroclimatic conditions. Journal of the Indian Society of Soil Science 45:503-505.

526 Fergusson JE. 1990. The heavy elements: chemistry, environmental impact adn health effects $\mid J a c k$

527 E. Fergusson.

528 Gamalero E, Glick BR. 2011. Mechanisms used by plant growth-promoting bacteria. In: Bacteria 529 in agrobiology: Plant nutrient management. Springer, 17-46.

530 Glick BR. 2012. Plant growth-promoting bacteria: mechanisms and applications. Scientifica 2012.

531 Glickmann E, Dessaux Y. 1995. A critical examination of the specificity of the salkowski reagent 532 for indolic compounds produced by phytopathogenic bacteria. Applied and environmental 533 microbiology 61:793-796.

534 Gontia-Mishra I, Sapre S, Sharma A, Tiwari S. 2016. Alleviation of mercury toxicity in wheat by 535 the interaction of mercury-tolerant plant growth-promoting rhizobacteria. Journal of Plant Growth 536 Regulation 35:1000-1012.

537 Goyer RA. 1997. Toxic and essential metal interactions. Annual review of nutrition 17:37-50.

538 Gyaneshwar P, Kumar GN, Parekh L, Poole P. 2002. Role of soil microorganisms in improving P 539 nutrition of plants. Plant and soil 245:83-93.

540 Hameeda B, Harini G, Rupela O, Wani S, Reddy G. 2008. Growth promotion of maize by 541 phosphate-solubilizing bacteria isolated from composts and macrofauna. Microbiological 542 research 163:234-242.

543 Hashem A, Abed K. 2002. Arsenic, lead and microorganisms in hair and nails of some women 544 from Saudi Arabia. Journal of Medical Science 2:82-84.

545 Höflich G, Wiehe W, Kühn G. 1994. Plant growth stimulation by inoculation with symbiotic and 546 associative rhizosphere microorganisms. Experientia 50:897-905.

547 Ionesco T, Sauvage C. 1969. Fichier des espèces climax. Al Awamia 32:105-124.

548 Islam S, Akanda AM, Prova A, Islam MT, Hossain MM. 2016. Isolation and identification of plant 549 growth promoting rhizobacteria from cucumber rhizosphere and their effect on plant growth 550 promotion and disease suppression. Frontiers in microbiology 6:1360.

551 Kamran S, Shazia A, Shahida H. 2010. Growth responses of Triticum aestivum to plant growth 552 promoting Rhizobacteria used as a biofertilizer. Research Journal of Microbiology 5:1022-1030.

553 Kang Y, Shen M, Xia D, Ye K, Zhao Q, Hu J. 2017. Caution of intensified spread of antibiotic 554 resistance genes by inadvertent introduction of beneficial bacteria into soil. Acta Agriculturae 555 Scandinavica, Section B-Soil \& Plant Science 67:576-582.

556 Kavitha T, Nelson R, Jesi S. 2013. Screening of rhizobacteria for plant growth promoting traits 557 and antifungal activity against charcoal rot pathogen Macrophomina phaseolina. International 558 Journal of Pharma and Bio Sciences 4.

559 Khan MWA, Ahmad M. 2006. Detoxification and bioremediation potential of a Pseudomonas 560 fluorescens isolate against the major Indian water pollutants. Journal of Environmental Science 561 and Health, Part A 41:659-674. 
562 Khan MS, Zaidi A, Ahemad M, Oves M, Wani PA. 2010. Plant growth promotion by phosphate

563

564

565

566

567

568

569

570

571

572

573

574

575

576

577

578

579

580

581

582

583

584

585

586

587

588

589

590

591

592

593

594

595

596

597

598

599

600

601

solubilizing fungi-current perspective. Archives of Agronomy and Soil Science 56:73-98.

Khan MS, Zaidi A, Ahmad E. 2014. Mechanism of phosphate solubilization and physiological functions of phosphate-solubilizing microorganisms. In: Phosphate solubilizing microorganisms. Springer, 31-62.

Khan MS, Zaidi A, Wani PA. 2007. Role of phosphate-solubilizing microorganisms in sustainable agriculture - a review. Agronomy for sustainable development 27:29-43.

Khan N, Zandi P, Ali S, Mehmood A, Adnan Shahid M, Yang J. 2018. Impact of salicylic acid and PGPR on the drought tolerance and phytoremediation potential of Helianthus annus. Frontiers in microbiology 9:2507.

Kluepfel DA. 1993. The behavior and tracking of bacteria in the rhizosphere. Annual review of phytopathology 31:441-472.

Koley TK, Kaur C, Nagal S, Walia S, Jaggi S. 2016. Antioxidant activity and phenolic content in genotypes of Indian jujube (Zizyphus mauritiana Lamk.). Arabian Journal of Chemistry 9:S1044S1052.

Kumar A, Kumar A, Devi S, Patil S, Payal C, Negi S. 2012. Isolation, screening and characterization of bacteria from Rhizospheric soils for different plant growth promotion (PGP) activities: an in vitro study. Recent research in science and technology 4:1-5.

Kunwar VS, Lamichhane J, Gauchan DP. 2018. Strategies to improve phosphorus availability in a sustainable agricultural system. Int. J. Innov. Sci. Res. Technol 3:323-331.

Lahlou M, El Mahi M, Hamamouchi J. 2002. Evaluation of antifungal and mollusuicidial activities of Moroccan Zizyphus lotus (L.) Desf. In: 410-414.

Ma Y, Rajkumar M, Luo Y, Freitas H. 2011. Inoculation of endophytic bacteria on host and nonhost plants - effects on plant growth and Ni uptake. Journal of Hazardous Materials 195:230237.

Ma QY, Traina SJ, Logan TJ, Ryan JA. 1994. Effects of aqueous Al, Cd, Cu, Fe (II), Ni, and Zn on $\mathrm{Pb}$ immobilization by hydroxyapatite. Environmental science \& technology 28:1219-1228.

Matthijs S, Tehrani KA, Laus G, Jackson RW, Cooper RM, Cornelis P. 2007. Thioquinolobactin, a Pseudomonas siderophore with antifungal and anti-Pythium activity. Environmental Microbiology 9:425-434.

Mazumdar D, Saha SP, Ghosh S. 2019. Isolation, screening and application of a potent PGPR for enhancing growth of Chickpea as affected by nitrogen level. International Journal of Vegetable Science:1-18.

Miransari M, Mackenzie A. 2010. Development of a soil $\mathrm{N}$ test for fertilizer requirements for corn production in Quebec. Communications in soil science and plant analysis 42:50-65.

Mitchell R, Alexander M. 1963. Lysis of soil fungi by bacteria. Canadian Journal of Microbiology 9:169-177.

Mohite B. 2013. Isolation and characterization of indole acetic acid (IAA) producing bacteria from rhizospheric soil and its effect on plant growth. Journal of soil science and plant nutrition 13:638649.

Peer] reviewing PDF | (2021:01:57105:2:1:NEW 17 May 2021) 
602 Montoya RIR, Cota FIP, de los Santos Villalobos S. 2019. Draft genome sequence of Bacillus 603 megaterium TRQ8, a plant growth-promoting bacterium isolated from wheat (Triticum turgidum 604 subsp. durum) rhizosphere in the Yaqui Valley, Mexico. 3 Biotech 9:201.

605 Msaky J, Calvet R. 1990. Adsorption behavior of copper and zinc in soils: influence of $\mathrm{pH}$ on 606 adsorption characteristics. Soil Science 150:513-522.

607 Nagpure A, Choudhary B, Gupta RK. 2014. Mycolytic enzymes produced by Streptomyces 608 violaceusniger and their role in antagonism towards wood-rotting fungi. Journal of Basic 609 Microbiology 54:397-407.

610 Narayanasamy G, Ghosh S, Sarkar M. 1981. Chemical and mineralogical composition of 611 phosphate rock deposits occurring in India. Fertiliser news.

612 Nautiyal CS. 1999. An efficient microbiological growth medium for screening phosphate 613 solubilizing microorganisms. FEMS microbiology Letters 170:265-270.

614 Niu D-D, Liu H-X, Jiang C-H, Wang Y-P, Wang Q-Y, Jin H-L, Guo J-H. 2011. The plant growth615 promoting rhizobacterium Bacillus cereus AR156 induces systemic resistance in Arabidopsis 616 thaliana by simultaneously activating salicylate-and jasmonate/ethylene-dependent signaling 617 pathways. Molecular Plant-Microbe Interactions 24:533-542.

618 Otieno N, Lally RD, Kiwanuka S, Lloyd A, Ryan D, Germaine KJ, Dowling DN. 2015. Plant 619 growth promotion induced by phosphate solubilizing endophytic Pseudomonas isolates. Frontiers 620 in microbiology 6:745.

621 Pandey P, Maheshwari D. 2007. Two-species microbial consortium for growth promotion of 622 Cajanus cajan. Current science:1137-1142.

623 Pérez-Montaño F, Alías-Villegas C, Bellogín R, Del Cerro P, Espuny M, Jiménez-Guerrero I, 624 López-Baena FJ, Ollero F, Cubo T. 2014. Plant growth promotion in cereal and leguminous 625 agricultural important plants: from microorganism capacities to crop production. Microbiological 626 research 169:325-336.

627 Pescod M. 1992. Wastewater treatment and use in agriculture.

628 Pizarro-Tobías P, Niqui JL, Roca A, Solano J, Fernández M, Bastida F, García C, Ramos JL. 2015. 629 Field trial on removal of petroleum-hydrocarbon pollutants using a microbial consortium for 630 bioremediation and rhizoremediation. Environmental Microbiology Reports 7:85-94.

631 Rahman CH, Ahcene B, Miloud B, Rachid D. 2017. Screening and characterization of plant growth 632 promoting traits of phosphate solubilizing bacteria isolated from wheat rhizosphere of Algerian 633 saline soil. Malaysian Journal of Microbiology 13:124-131.

634 Raj SN, Deepak S, Basavaraju P, Shetty H, Reddy M, Kloepper JW. 2003. Comparative 635 performance of formulations of plant growth promoting rhizobacteria in growth promotion and 636 suppression of downy mildew in pearl millet. Crop Protection 22:579-588.

637 Raj SN, Shetty NP, Shetty H. 2004. Seed bio-priming with Pseudomonas fluorescens isolates 638 enhances growth of pearl millet plants and induces resistance against downy mildew. International 639 Journal of Pest Management 50:41-48.

640 Raju N, Niranjana S, Janardhana G, Prakash H, Shetty HS, Mathur S. 1999. Improvement of seed 641 quality and field emergence of Fusarium moniliforme infected sorghum seeds using biological 
642 agents. Journal of the Science of Food and Agriculture 79:206-212.

643 Ramakrishna W, Yadav R, Li K. 2019. Plant growth promoting bacteria in agriculture: Two sides 644 of a coin. Applied Soil Ecology 138:10-18.

645 RSAISSI N, BENCHARKI B. 2012. Importance and agro-economical impact of wild jujube 646 (Ziziphus lotus) in Chaouia region. : $\mathrm{N}^{\circ} 3: 13-27$.

647 Schwyn B, Neilands J. 1987. Universal chemical assay for the detection and determination of 648 siderophores. Analytical biochemistry 160:47-56.

649 Sharma RK, Agrawal M, Marshall FM. 2008. Atmospheric deposition of heavy metals $(\mathrm{Cu}, \mathrm{Zn}$, $650 \mathrm{Cd}$ and $\mathrm{Pb}$ ) in Varanasi city, India. Environmental Monitoring and Assessment 142:269-278.

651 Sharma SB, Sayyed RZ, Trivedi MH, Gobi TA. 2013. Phosphate solubilizing microbes: 652 sustainable approach for managing phosphorus deficiency in agricultural soils. SpringerPlus $6532: 587$.

654 Shilev S. 2013. Soil rhizobacteria regulating the uptake of nutrients and undesirable elements by 655 plants. In: Plant microbe symbiosis: Fundamentals and advances. Springer, 147-167.

656 Singh A, Sharma RK, Agrawal M, Marshall FM. 2010. Risk assessment of heavy metal toxicity 657 through contaminated vegetables from waste water irrigated area of Varanasi, India. Tropical 658 ecology 51:375-387.

659 Tangahu BV, Sheikh Abdullah SR, Basri H, Idris M, Anuar N, Mukhlisin M. 2011. A review on 660 heavy metals $(\mathrm{As}, \mathrm{Pb}$, and $\mathrm{Hg}$ ) uptake by plants through phytoremediation. International Journal 661 of Chemical Engineering 2011.

662 Thomas B, Murphy DJ, Murray BG. 2016. Encyclopedia of applied plant sciences. Academic 663 Press.

664 Trivedi P, Pandey A, Palni LMS, Bag N, Tamang M. 2004. Colonization of rhizosphere of tea by 665 growth promoting bacteria.

666 Van Goethem MW, Pierneef R, Bezuidt OK, Van De Peer Y, Cowan DA, Makhalanyane TP. 667 2018. A reservoir of 'historical'antibiotic resistance genes in remote pristine Antarctic soils. 668 Microbiome 6:40.

669 Wang B, Huang Q, Venkitasamy C, Chai H, Gao H, Cheng N, Cao W, Lv X, Pan Z. 2016. Changes 670 in phenolic compounds and their antioxidant capacities in jujube (Ziziphus jujuba Miller) during 671 three edible maturity stages. LWT-Food Science and Technology 66:56-62.

672 Went FW, Thimann KV. 1937. Phytohormones. Phytohormones.

673 Whitelaw MA. 1999. Growth promotion of plants inoculated with phosphate-solubilizing fungi. 674 In: Advances in agronomy. Elsevier, 99-151.

675 Yadav J, Verma JP, Tiwari KN. 2010. Effect of plant growth promoting rhizobacteria on seed 676 germination and plant growth chickpea (Cicer arietinum L.) under in vitro conditions. In: Citeseer, $677 \quad 15-18$.

678 Zaidi A, Khan M, Ahemad M, Oves M. 2009. Plant growth promotion by phosphate solubilizing 679 bacteria. Acta microbiologica et immunologica Hungarica 56:263-284.

680 Zhang M, Yang L, Hao R, Bai X, Wang Y, Yu X. 2020. Drought-tolerant plant growth-promoting 681 rhizobacteria isolated from jujube (Ziziphus jujuba) and their potential to enhance drought 
682 tolerance. Plant and Soil 452:423-440.

683 Zhao L, Xu Y, Lai X-H, Shan C, Deng Z, Ji Y. 2015. Screening and characterization of endophytic

684 Bacillus and Paenibacillus strains from medicinal plant Lonicera japonica for use as potential plant 685 growth promoters. Brazilian Journal of Microbiology 46:977-989.

686 


\section{Figure 1}

Phosphate solubilization by isolated strains.

Concentrations of solubilized P released in NBRIP broth of isolated PSB strains and the resulting $\mathrm{pH}$ of culture supernatants indicated by the blue line. C (Negative control: noninoculated medium), RT (Rhizobium tropici: positive control). The values represent means of 3 replicates $(n=3) \pm$ standard deviations. Different letters indicate significant differences at $p$ $<0.05$. 


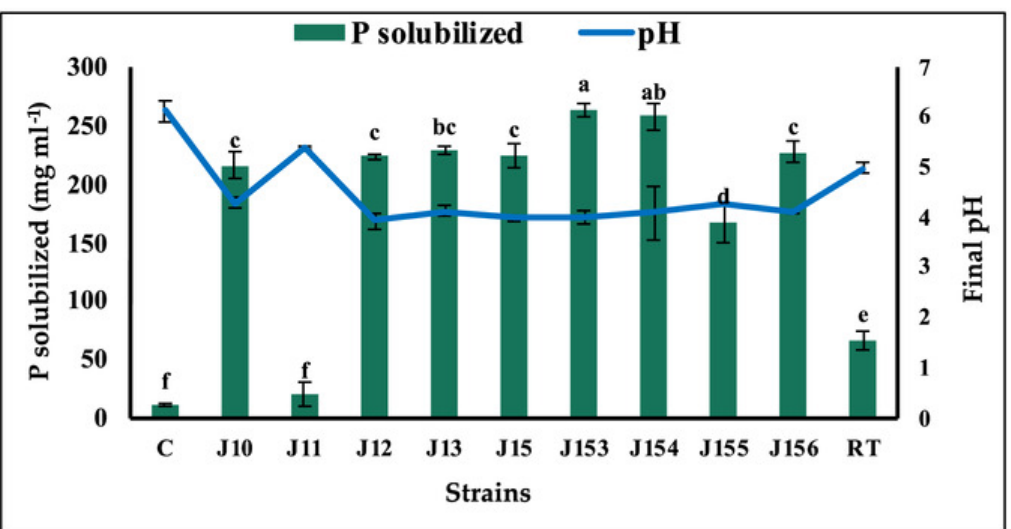




\section{Figure 2}

\section{Phylogenetic tree of isolated strains.}

Neighbor-joining phylogenetic tree showing relationship between the selected PSB from jujube soil and their representative species from NCBI database, built using UGENE Software. Multiple alignment of 16S rRNA gene sequences was performed using NCBI database

Tree scale: 0.01

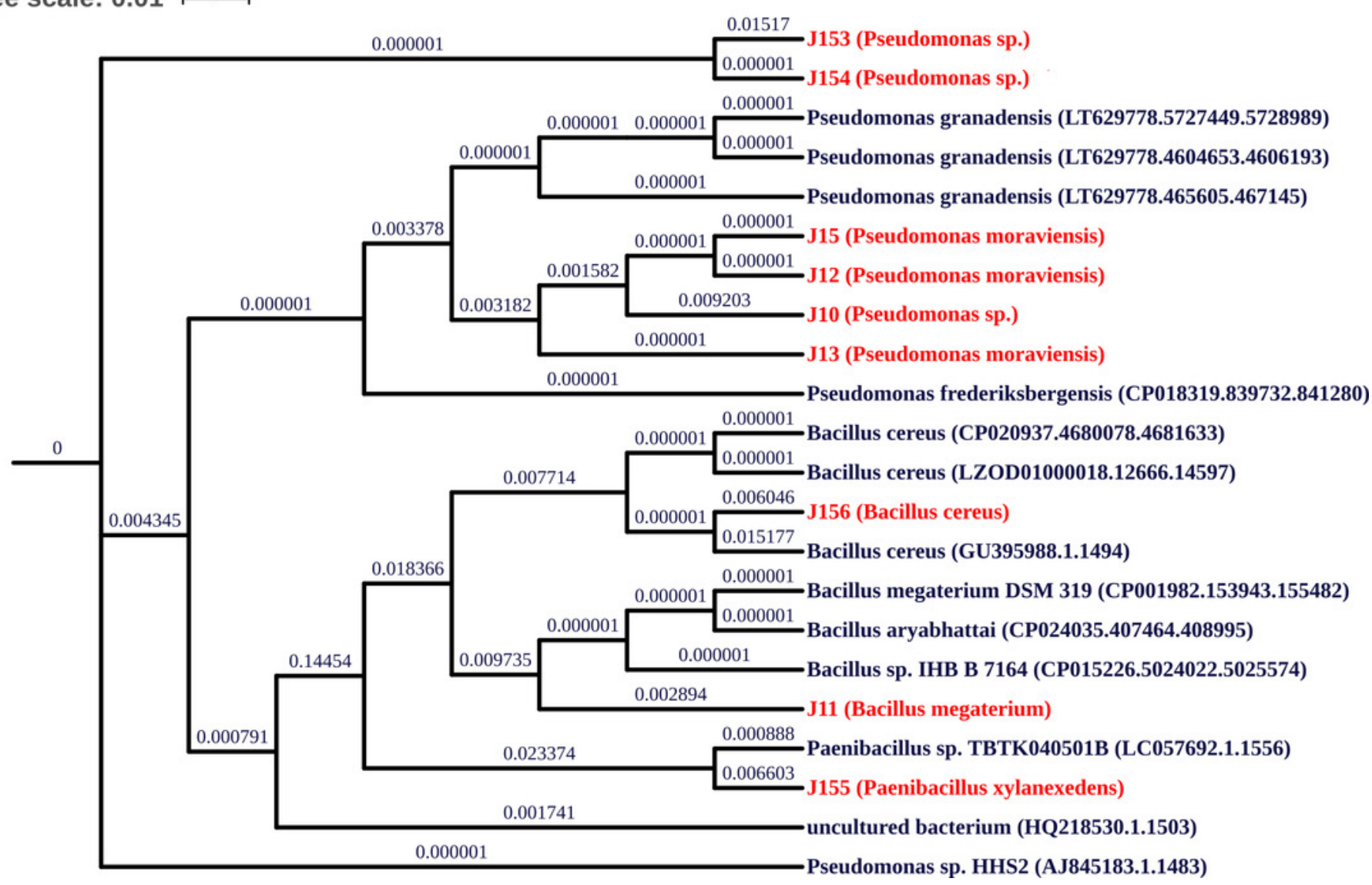




\section{Figure 3}

Indole acetic acid production by isolated strains.

Indole acetic acid production by selected PSB in the TSB broth amended with $0,1 \%$ of Ltryptophan. C (Negative control: non-inoculated medium). The values represent means of 3 replicates $(n=3) \pm$ standard deviations. Different letters indicate significant differences at $p$ $<0.05$. 


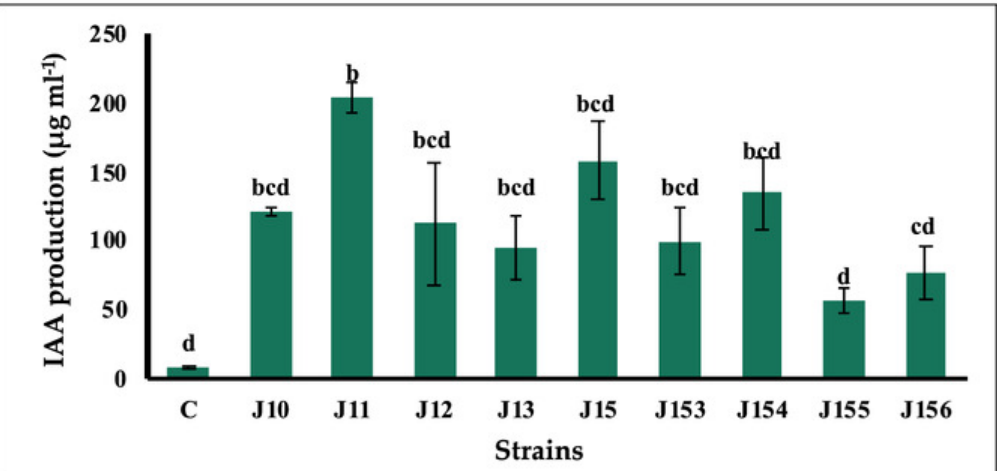


Figure 4

Ammonia production by isolated strains.

Ammonia production by selected PSB. C (Negative control: non-inoculated medium). The values represent means of 3 replicates $(n=3) \pm$ standard deviations. Different letters indicate significant differences at $p<0.05$. 


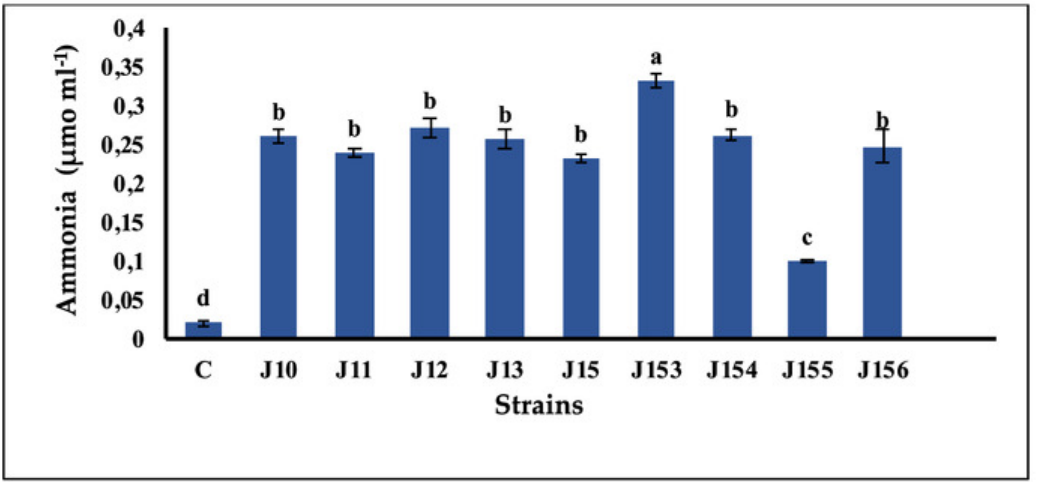




\section{Figure 5}

Effect of bacterial inoculation of wheat seed germination parameters.

Effect of bacterial inoculation of wheat seed germination parameters. (A) Germination rate after 24 and $48 \mathrm{~h}$ of incubation (B) Total length of shoots and roots after 7 days, (C) Fresh weight of shoots and roots after 7 days, (D) Dry weight of shoots and roots after 8 days, (E) Seedling vigor index. c (Negative control: no-inoculated seeds). Different letters indicate significant differences at $p<0.05$. 


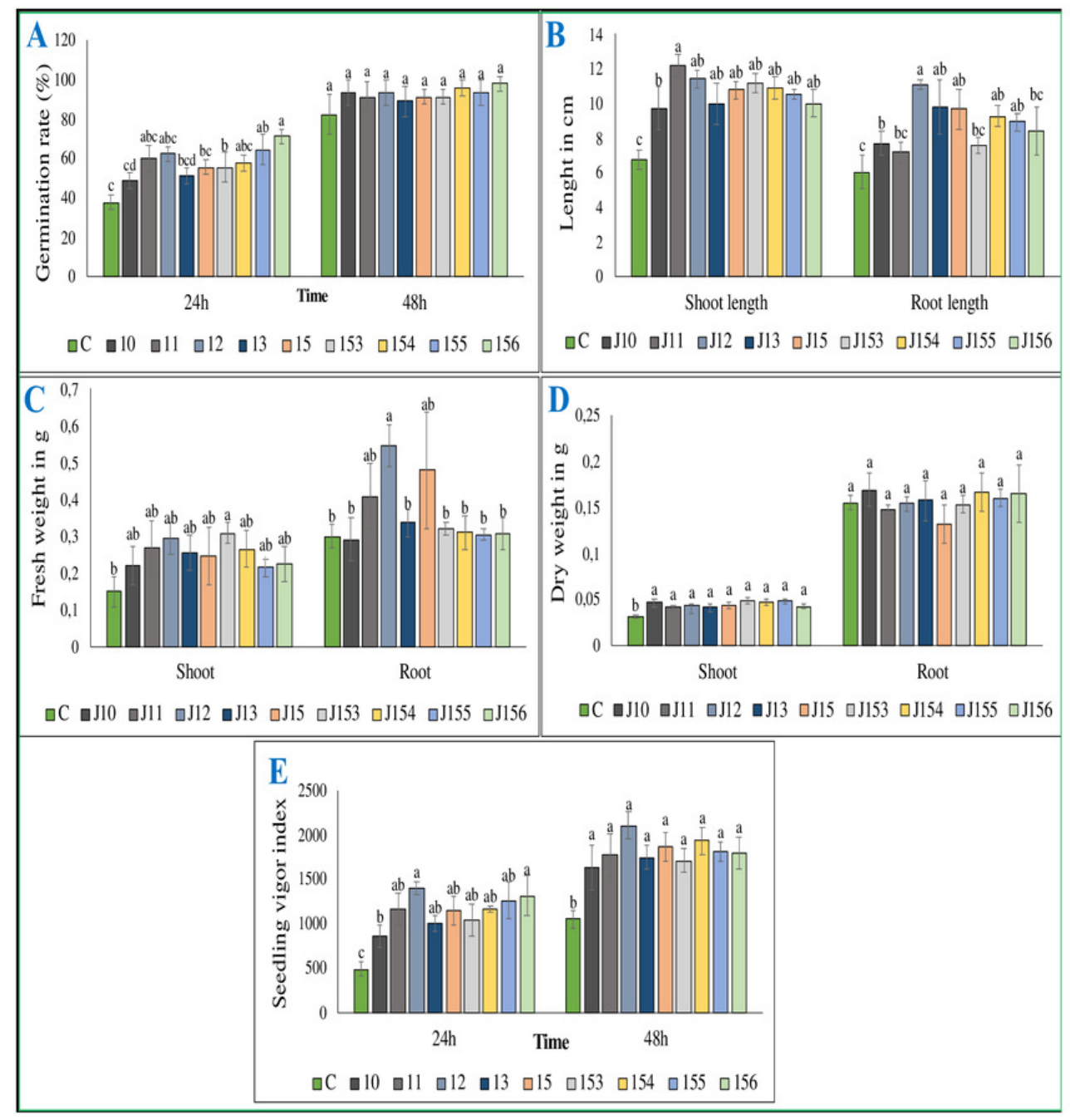




\section{Figure 6}

Effect of studied strains on shoots and roots growth.

Effect on shoots and roots growth after seven days of inoculation of wheat seeds by the four pseudomonas strains: P. moraviensis J13, Pseudomonas Sp. J10, J153 and J154 (C-:control non-iniculated seeds).
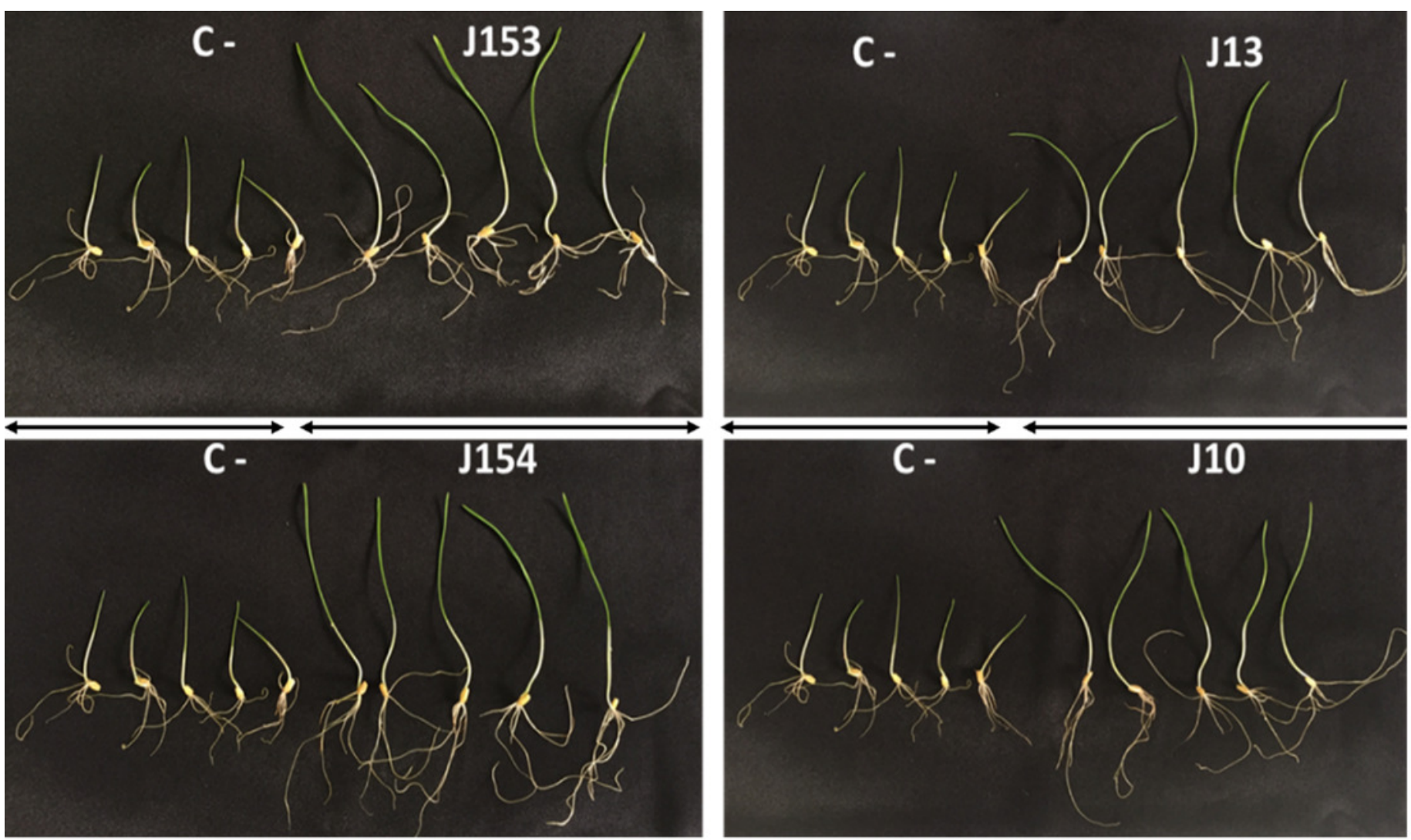


\section{Table 1 (on next page)}

Selected physicochemical properties of the studied Jujube plant soil samples. 
1

2

3

\begin{tabular}{clc}
\hline \multicolumn{1}{c}{ Parameters } & & Results \\
\hline & Clay & 21,00 \\
Granulometry (\%) & Fine silt & 21,30 \\
(AFNOR NF X31-107) & Coarse silt & 11,50 \\
& Fine sand & 21,50 \\
& Coarse sand & 22,60 \\
\hline Exchangeable elements (mg/kg) & $\mathrm{K}_{2} \mathrm{O}$ & 749 \\
(AFNOR NF X31-108) & $\mathrm{MgO}$ & 431 \\
& $\mathrm{CaO}$ & 8071 \\
\hline pH-H $\mathrm{H}_{2} \mathrm{O}$ (NF ISO 10390) & $\mathrm{Na}_{2} \mathrm{O}$ & 208 \\
Electrical conductivity mS/cm (NF ISO 11265) & & 8,7 \\
Total limestone (\%) (NF ISO 10693) & & 0,15 \\
Organic matter (\%) (NF ISO 14235) & & 2,50 \\
Oslen Phosphorus (mg/kg) (NF ISO 11263) & & 2,92 \\
\hline
\end{tabular}
Table 1. Physicochemical properties of the studied soil samples.

4

5

6 


\section{Table 2 (on next page)}

Molecular identification of selected PSB using 16S rRNA gene sequencing. 
1

2 Table 2. Molecular identification of selected PSB using 16S rRNA gene sequencing.

\begin{tabular}{llcl}
\hline Isolate & Closest species & Identity (\%) & Accession No. \\
\hline J10 & Pseudomonas sp. & 98 & MT771625 \\
$\mathbf{J 1 1}$ & Bacillus megaterium & 98 & MT771626 \\
$\mathbf{J 1 2}$ & Pseudomonas moraviensis & 98 & MT771627 \\
$\mathbf{J 1 3}$ & Pseudomonas moraviensis & 98 & MT771628 \\
$\mathbf{J 1 5}$ & Pseudomonas moraviensis & 98 & MT771629 \\
$\mathbf{J 1 5 3}$ & Pseudomonas sp. & 99 & MT771630 \\
$\mathbf{J 1 5 4}$ & Pseudomonas sp. & 98 & MT771631 \\
$\mathbf{J 1 5 5}$ & Paenibacillus $x y l a n e x e d e n s$ & 98 & MT771632 \\
$\mathbf{J 1 5 6}$ & Bacillus cereus & 99 & MT771633 \\
\hline
\end{tabular}

3

4 


\section{Table 3 (on next page)}

Summary table of relevant phenotypic traits observed in selected PSB using plate assay.

The ' + ' and ' - ' signs indicate efficiencies as follow: - , negative result; + , weakly positive; ++ , moderately positive; +++ , highly positive. The ' $R$ ' means resistance to antibiotic. Final concentrations: chloramphenicol (Cm) $20 \mu \mathrm{g} . \mathrm{mL}-1$; kanamycin (Kan) $50 \mu \mathrm{g} . \mathrm{mL}-1$ ampicillin (Amp) $100 \mu \mathrm{g} . \mathrm{mL}-$ 
1

2 Table 3. Summary table of relevant phenotypic traits observed in selected PSB using plate assay.

3

\begin{tabular}{lcccc}
\hline \multirow{2}{*}{ Strain } & Antibiotic Resistance & $\begin{array}{c}\text { Siderophores } \\
\text { production }\end{array}$ & \multicolumn{2}{c}{ Extracellular Enzymes } \\
\cline { 4 - 5 } & & ++ & Proteases & Cellulase \\
\hline Pseudomonas $\mathrm{sp} . \mathrm{J} 10$ & $\mathrm{Amp}^{\mathrm{R}}, \mathrm{Cm}^{\mathrm{R}}, \mathrm{Spect}^{\mathrm{R}}$ & - & + & + \\
B. megaterium $\mathrm{J} 11$ & $\mathrm{Amp}^{\mathrm{R}}, \mathrm{Cm}^{\mathrm{R}}$ & ++ & + & - \\
P. moraviensis $\mathrm{J} 12$ & $\mathrm{Amp}^{\mathrm{R}}, \mathrm{Cm}^{\mathrm{R}}, \mathrm{Spect}^{\mathrm{R}}$ & +++ & + & - \\
P. moraviensis $\mathrm{J} 13$ & $\mathrm{Amp}^{\mathrm{R}}, \mathrm{Cm}^{\mathrm{R}}$ & ++ & + & - \\
P. moraviensis $\mathrm{J} 15$ & $\mathrm{Amp}^{\mathrm{R}}, \mathrm{Cm}^{\mathrm{R}}$ & ++ & - & - \\
Pseudomonas $\mathrm{sp} . \mathrm{J} 153$ & $\mathrm{Amp}^{\mathrm{R}}, \mathrm{Cm}^{\mathrm{R}}$ & ++ & - & - \\
Pseudomonas $\mathrm{sp} . \mathrm{J} 154$ & $\mathrm{Kan}^{\mathrm{R}}, \mathrm{Spect}^{\mathrm{R}}$ & ++ & + & + \\
Paenibacillus $x y$ lanexedens $\mathrm{J} 155$ & - & + & + & + \\
B. cereus $\mathrm{J} 156$ & - & &
\end{tabular}

4

5 
Table 4 (on next page)

Heavy metals tolerance of selected PSB strains

+ for tolerance, - for sensitivity 
1

2 Table 4. Heavy metals tolerance of selected PSB strains

3

\begin{tabular}{|c|c|c|c|c|c|c|c|c|c|c|c|c|}
\hline \multirow{2}{*}{ Strain } & \multicolumn{4}{|c|}{$\mathrm{CuSO}_{4} . \mathbf{5} \mathrm{H}_{2} \mathrm{O}$ (mg.L-1) } & \multicolumn{4}{|c|}{$\mathrm{CdSO}_{4}$ (mg.L-1) } & \multicolumn{4}{|c|}{$\mathbf{N}_{2} \mathbf{N i O}_{6}\left(\mathrm{mg} \cdot \mathrm{L}^{-1}\right)$} \\
\hline & 0.3 & 0.5 & 1 & 1.5 & 0.3 & 0.5 & 1 & 1.5 & 0.3 & 0.5 & 1 & 1.5 \\
\hline Pseudomonas sp. J10 & + & + & - & - & + & - & - & - & + & + & + & + \\
\hline B. megaterium $\mathrm{J} 11$ & + & - & - & - & - & - & - & - & + & + & - & - \\
\hline P. moraviensis $\mathrm{J} 12$ & + & + & - & - & + & - & - & - & + & + & - & - \\
\hline P. moraviensis $\mathrm{J} 13$ & + & + & - & - & + & - & - & - & + & + & - & - \\
\hline Pseudomonas sp. J153 & + & + & + & + & + & + & + & + & + & + & - & - \\
\hline Pseudomonas sp. J154 & - & - & - & - & + & - & - & - & + & + & - & - \\
\hline Paenibacillus xylanexedens J155 & + & - & - & - & - & - & - & - & + & - & - & - \\
\hline B. cereus $\mathrm{J} 156$ & + & + & + & - & + & - & - & - & + & + & + & + \\
\hline E. coli $\mathrm{DH} 5 \alpha$ & + & + & + & - & + & - & - & - & + & + & - & - \\
\hline
\end{tabular}

$4+$ for tolerance, - for sensitivity

5

6 